\title{
Prognostic value of Ki67 and p53 in patients with estrogen receptor-positive and human epidermal growth factor receptor 2-negative breast cancer: Validation of the cut-off value of the Ki67 labeling index as a predictive factor
}

\author{
MASAHIRO OHARA $^{1}$, KAZUO MATSUURA ${ }^{1}$, ETSUSHI AKIMOTO ${ }^{1}$, MIDORI NOMA $^{1}$, MIHOKO DOI $^{2}$, \\ TAKASHI NISHIZAKA ${ }^{3}$, NAOKI KAGAWA ${ }^{4}$ and TOSHIYUKI ITAMOTO ${ }^{1}$ \\ Departments of ${ }^{1}$ Breast Surgery, ${ }^{2}$ Clinical Oncology and ${ }^{3}$ Clinical Laboratory, Hiroshima Prefectural Hospital, \\ Hiroshima 734-8530; ${ }^{4}$ Kagawa Breast Clinic, Hiroshima 730-0029, Japan
}

Received May 20, 2015; Accepted January 25, 2016

DOI: $10.3892 / \mathrm{mco} .2016 .776$

\begin{abstract}
The aim of this study was to evaluate the significance of the Ki67 labeling index and p53 status as prognostic and predictive indicators of operable estrogen receptor (ER)-positive and human epidermal growth factor receptor 2 (HER2)-negative breast cancer. Among 697 consecutive patients with primary breast cancer who underwent curative surgery between 2002 and 2013, 308 patients with ER-positive and HER2-negative breast cancer were assessed. The results of the multivariate Cox analysis demonstrated that a high Ki67 labeling index was significantly associated with a short recurrence-free interval (RFI) $(\mathrm{P}=0.004)$ and was marginally associated with a worse overall survival $(\mathrm{P}=0.074)$. A positive $\mathrm{p} 53$ status was not associated with worse outcomes. To validate the cut-off values of the Ki67 labeling index for identifying patients who may benefit from additional chemotherapy, prognostic factors were investigated in breast cancer patients treated postoperatively with endocrine therapy alone. Analysis of receiver operating characteristic curves demonstrated that a Ki67 labeling index cut-off of $20.0 \%$ was optimal for predicting recurrence among patients who did not receive adjuvant chemotherapy. The 5-year RFIs for patients with $\mathrm{Ki} 67<20$ and $\geq 20 \%$ were 97.2 and $86.6 \%$,
\end{abstract}

Correspondence to: Dr Masahiro Ohara, Department of Breast Surgery, Hiroshima Prefectural Hospital, 1-5-54 Ujina-Kanda, Minami-Ku, Hiroshima 734-8530, Japan

E-mail: oharamas@hotmail.com

Abbreviations: AUC, area under the curve; CI, confidence interval; ER, estrogen receptor; FISH, fluorescent in situ hybridization; HER2, human epidermal growth factor receptor 2; HR, hazard ratio; IHC, immunohistochemistry; OS, overall survival; PgR, progesterone receptor; RFI, recurrence-free interval; ROC, receiver operating characteristic

Key words: breast cancer, Ki67, p53, prognostic factor, predictive factor respectively $(\mathrm{P}=0.0244)$. A high Ki67 labeling index $(\geq 20 \%)$ was significantly associated with large tumors $(\mathrm{P}<0.01)$, lymph node metastasis $(\mathrm{P}=0.0236)$ and positive p53 status $(\mathrm{P}<0.001)$. The univariate analysis demonstrated that Ki67 labeling index $\geq 20 \%$, lymph node metastasis and progesterone receptor negativity were significant worse prognostic factors for RFI ( $\mathrm{P}=0.0333,0.0116$ and 0.0573 , respectively). The Ki67 labeling index was found to be a useful prognostic factor in patients with ER-positive and HER2-negative breast cancer and the cut-off values of the Ki67 labeling index for making a decision regarding adjuvant treatment were validated.

\section{Introduction}

For the majority of patients with early breast cancer, adjuvant systemic therapy is recommended following primary surgery to reduce the risk of breast cancer recurrence and to increase the likelihood of a cure. Approximately $70 \%$ of breast cancers express estrogen receptor (ER), and ER status is a powerful predictor of response to therapies that inhibit estrogen synthesis or block the action of its receptor (1). Endocrine therapies are established in the adjuvant setting (2-4). It is important to distinguish patients with ER-positive tumors at high risk for recurrence who require additional chemotherapy, from those for whom adjuvant endocrine therapy alone may suffice, as the economic burden and toxicities of chemotherapy must be minimized (5). Multi-gene assays are strong candidate tools for predicting the risk of recurrence in ER-positive patients (6). However, classification using multi-gene expression analyses is not appropriate for everyday practice. According to the St. Gallen Consensus Conference held in 2013, the intrinsic subtype affects the indication for adjuvant chemotherapy and surrogate definitions of subtype may be obtained by immunohistochemistry (IHC) of ER, progesterone receptor (PgR), Ki67 and human epidermal growth factor receptor 2 (HER2) (7).

For practical purposes, in order to reliably distinguish between 'luminal A' (more endocrine-sensitive, more indolent and better prognosis) and 'luminal B (HER2-negative)' (less endocrine-sensitive, more aggressive and worse prognosis) 
breast cancer subtypes, Ki67 may be used as a proliferative index in addition to ER and PgR status. At the St. Gallen Consensus Conference, the majority of the expert panel voted that a threshold of $\geq 20 \%$ should be defined as 'high' Ki-67 status (7). The cut-off value of Ki67 for high proliferation remains unclear.

Breast cancers expressing high levels of $\mathrm{Ki67}$, which is a nuclear marker of cell proliferation, are associated with worse outcomes (8-10). However, a standard operating procedure has not been established, and the inter-laboratory and inter-study comparabilities of Ki67 are limited (11-13). Therefore, laboratory-specific procedures and cut-off values must be examined in order to use $\mathrm{Ki} 67$ as an appropriate prognostic marker (7).

Recent studies have demonstrated that abnormalities of the p53 gene and accumulation of the p53 protein in the nuclei are prognostic indicators in ER-positive and HER2-negative breast cancer patients (14-17). Whole-genome analysis identified the presence of a p53 gene mutation in $12 \%$ of luminal A and $32 \%$ of luminal B breast cancers (18). Therefore, the expression of p53 has been suggested to be useful in distinguishing between luminal A and B subtypes. However, p53 assessment is not recommended for routine clinical use in breast cancer.

The present study aimed to determine the clinical value of Ki67 and p53 as prognostic markers in patients with ER-positive and HER2-negative breast cancer, in order to help stratify patients into prognostic subgroups with a better predictive response to adjuvant treatment.

\section{Patients and methods}

Patients. Between February, 2002 and March,2013,697 consecutive patients with primary breast cancer underwent curative surgery at our institution. Among 615 patients with invasive breast cancer, 85 who received preoperative chemotherapy and 161 with ER-negative, HER2-negative, or unknown subtypes were excluded from the analysis. A total of 6 patients with unknown Ki67 labeling indices and 55 who did not undergo endocrine therapy were also excluded. Data from 308 patients with a median age of 59.0 years (range, 26-91 years) and ER-positive/HER2-negative breast cancer, who were treated with endocrine therapy, were finally analyzed (Fig. 1). Patients who were considered to be at high risk according to prevalent breast cancer guidelines received chemotherapy (19-23). The follow-up period (median, 57.9 months) was terminated on 31 December, 2013. Demographic and medical data including age, type of breast surgery and a history of treatment for breast cancer and endocrine therapy were collected from medical charts. The Institutional Review Board approved this study (approval no. H25-98) and waived the requirement for informed consent from individual patients.

Clinicopathological factors. Clinicopathological factors such as age, tumor size, lymph node metastasis, nuclear grade, lymphovascular invasion positivity and $\mathrm{PgR}$ positivity, which are established prognostic factors for breast cancer, were compared between patients assigned to groups based on Ki67 labeling index cut-offs. Nuclear grade was determined according to the General Rules for Clinical and Pathological Recording of Breast Cancer, 16th edition (24). ER and PgR positivity was assessed by IHC and scored according to the Allred system (25). HER2

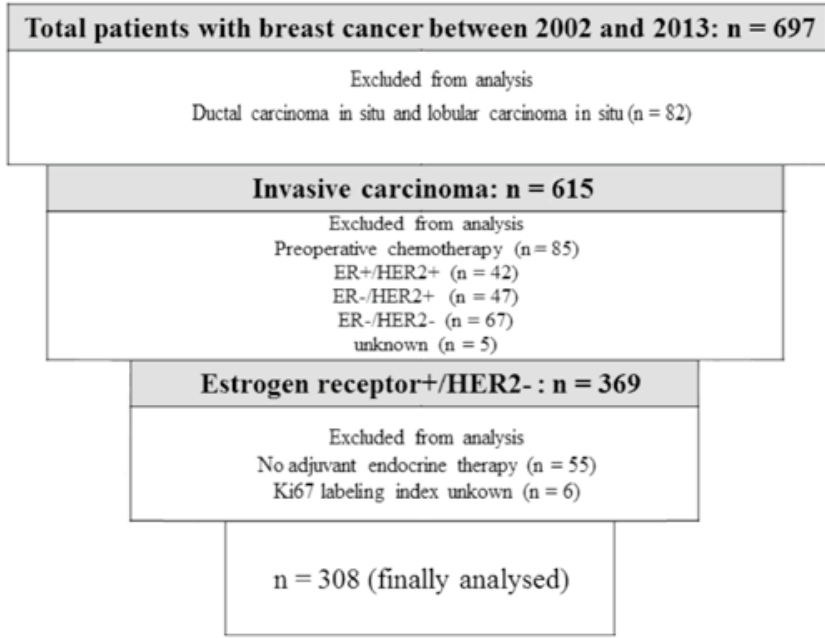

Figure 1. Patient selection process. ER, estrogen receptor. HER2, human epidermal growth factor receptor 2 .

positivity was defined as $3^{+}$by IHC or $2^{+}$by gene amplification using fluorescent in situ hybridization (FISH) $>2.0$.

The surgical specimens were stained using mouse monoclonal anti-Ki67 antibody (MIB-1; M7240; dilution 1:80; Dako, Glostrup, Denmark) and mouse DO-7 anti-p53 antibody (DO-7; dilution 1:800; cat. no. NCL-L-p53-DO7; Leica-Novocastra Laboratories Ltd., Newcastle upon Tyne, UK). Areas of dense staining were selected under a microscope, and >500 cancer cells were assessed to determine the levels of Ki67 expression. Ki67 immunoreactivity was recorded as a continuous variable based on the proportion of positive tumor cells (0-100\%), regardless of staining intensity. Cells with nuclear p53 immunostaining were defined as positive. When $<10$ or $\geq 10 \%$ of tumor cells expressed p53, the specimens were defined as negative or positive, respectively, for p53 expression (26).

Follow-up. All the patients were followed up from the day of surgery onwards. Follow-up care plans included regular physical examinations and annual mammograms. Recurrence was defined as any unequivocal occurrence of new cancer foci in a hitherto disease-free patient. The site of the first cancer recurrence and the interval between surgery and recurrence were determined. The recurrence-free interval (RFI) was calculated as the elapsed time between the date of surgery and that of the first confirmation of cancer recurrence or the last clinical contact attesting to recurrence-free status. Overall survival (OS) was defined as the interval from the day of surgery until death from any cause.

Statistical analysis. Data are presented as numbers (\%) or as means unless otherwise stated. Frequencies were compared using the $\chi^{2}$ test for categorical variables, and small samples were assessed using the Fisher's exact test. The patient population was subdivided according to the Ki67 labeling index cut-offs, and the duration of RFI was determined using Kaplan-Meier analyses. Differences in RFI were assessed using the log-rank test. The potential independent effects of the Ki67 labeling index on RFI and OS were determined by multivariate analyses using a Cox proportional hazards model that included variables with $\mathrm{P}<0.05$ in the univariate analyses 


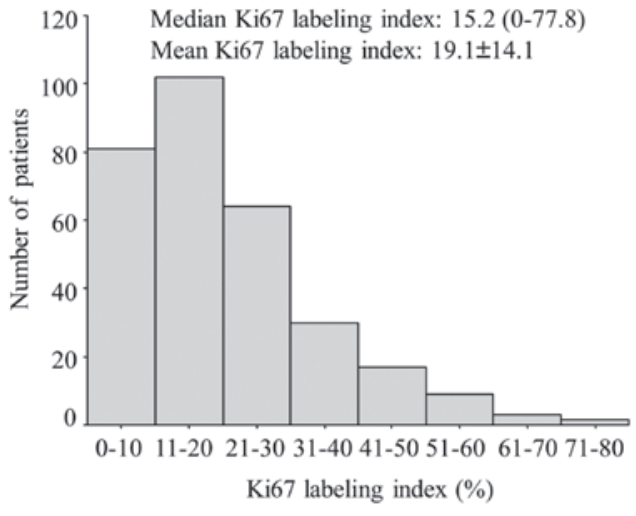

Figure 2. Distribution of patients according to the Ki67 labeling index.

and $\mathrm{P}<0.05$ was considered to indicate a statistically significant difference. Receiver operating characteristic (ROC) curves of the Ki67 labeling index for the prediction of recurrence were generated to determine the cut-off that yielded optimal sensitivity and specificity according to the Youden index. Data were statistically analyzed using EZR (27), which is a graphical user interface for R (version 2.13.0; The R Foundation for Statistical Computing, Vienna, Austria). More precisely, it is a modified version of $\mathrm{R}$ commander (version 1.6-3) that was designed to add statistical functions frequently used in biostatistics.

\section{Results}

Characteristics of patients and tumors. The clinicopathological characteristics of the 308 patients included in this study are summarized in Table I. The tumors were mainly ductal (91.6\%) or lobular (1.6\%) invasive carcinomas. The majority of the patients had pathological T1-stage tumors, 20 (6.5\%) had lymph node involvement, $248(80.5 \%)$ of the tumors were positive for lymphovascular invasion, and 257 (83.5\%) were PgR-positive on IHC. Adjuvant chemotherapy had been administered to $86(27.9 \%)$ patients. A total of 24 patients developed recurrence and 8 succumbed to the disease during the follow-up period. The distribution of the patients according to the Ki67 labeling index, ranging from 0 to $77.8 \%$ (median, 15.2\%), is shown in Fig. 2.

Univariate and multivariate analyses of RFI and OS. The variables included in the univariate analysis of RFI of the 308 patients were age, tumor size, nodal status, nuclear grade, lymphovascular invasion status, PgR status, Ki67 labeling index, p53 status and adjuvant chemotherapy. Positive nodal status and a high Ki67 labeling index were significantly associated with a short RFI. Moreover, a multivariate analysis that included nodal status and the Ki67 labeling index, identified positive nodal status [hazard ratio $(\mathrm{HR})=8.92,95 \%$ confidence interval (CI): 3.79-21.0, $\mathrm{P}<0.001]$ and a high Ki67 labeling index (HR=1.03, 95\% CI: 1.01-1.06, $\mathrm{P}=0.004)$ as independent prognostic factors for RFI (Table II). Larger tumors, positive nodal status and a high Ki67 labeling index were significantly associated with a short OS. A multivariate analysis that included tumor size, nodal status and Ki67 labeling index identified positive nodal status (HR=29.5, 95\% CI: 4.91-177.0, $\mathrm{P}<0.001)$ as an independent prognostic factor for OS. A high
Table I. Patient characteristics $(\mathrm{n}=308)$.

\begin{tabular}{|c|c|}
\hline Characteristics & No. $(\%)$ \\
\hline Age, years [median (range)] & $59.0(26-91)$ \\
\hline \multicolumn{2}{|l|}{ Histology } \\
\hline IDC & 282 (91.6) \\
\hline ILC & $5(1.6)$ \\
\hline Others & $21(6.8)$ \\
\hline \multicolumn{2}{|l|}{ pT stage } \\
\hline $\mathrm{T} 1$ & $226(73.4)$ \\
\hline $\mathrm{T} 2$ & $67(21.8)$ \\
\hline $\mathrm{T} 3$ & $1(0.3)$ \\
\hline $\mathrm{T} 4$ & $14(4.5)$ \\
\hline \multicolumn{2}{|l|}{ Nodal status } \\
\hline Negative & $288(93.5)$ \\
\hline Positive & $20(6.5)$ \\
\hline \multicolumn{2}{|l|}{ Nuclear grade } \\
\hline I & $38(12.3)$ \\
\hline II & $214(69.5)$ \\
\hline III & $32(10.4)$ \\
\hline Unknown & $24(7.8)$ \\
\hline \multicolumn{2}{|l|}{ Lymphovascular invasion } \\
\hline Negative & $57(18.5)$ \\
\hline Positive & $248(80.5)$ \\
\hline Unknown & $3(1.0)$ \\
\hline \multicolumn{2}{|l|}{ Progesterone receptor status } \\
\hline Negative & $50(16.2)$ \\
\hline Positive & $257(83.5)$ \\
\hline Unknown & $1(0.3)$ \\
\hline Ki67 labeling index, \% [median (range)] & $15.2(0.0-77.8)$ \\
\hline \multicolumn{2}{|l|}{ p53 status } \\
\hline Positive & $83(26.9)$ \\
\hline Negative & $225(73.1)$ \\
\hline \multicolumn{2}{|l|}{ Type of surgery } \\
\hline Breast-conserving surgery & $221(71.8)$ \\
\hline Modified radical mastectomy & $87(28.2)$ \\
\hline \multicolumn{2}{|l|}{ Endocrine therapy } \\
\hline Tamoxifen & $88(28.5)$ \\
\hline Tamoxifen + Gn-RH agonist & $40(13.0)$ \\
\hline Gn-RH agonist & $3(1.0)$ \\
\hline Anastrozole & $97(31.5)$ \\
\hline Letrozole & $76(24.7)$ \\
\hline Exemestane & $4(1.3)$ \\
\hline Chemotherapy & $86(27.9)$ \\
\hline Oral 5-FU & $4(1.3)$ \\
\hline Anthracycline & $29(9.4)$ \\
\hline Anthracycline + taxane & $35(11.4)$ \\
\hline $\mathrm{CMF}$ & $2(0.6)$ \\
\hline $\mathrm{TC}$ & $16(5.2)$ \\
\hline \multicolumn{2}{|l|}{ Recurrence } \\
\hline Local & $11(3.6)$ \\
\hline Distant & $13(4.2)$ \\
\hline No event & $284(92.2)$ \\
\hline Death & $8(2.5)$ \\
\hline
\end{tabular}

IDC, invasive ductal carcinoma; ILC, invasive lobular carcinoma; Gn-RH, gonadotrophin-releasing hormone; 5-FU, 5-fluorouracil; CMF, cyclophosphamide, methotrexate and 5-fluorouracil; TC, docetaxel and cyclophosphamide. 
Table II. Univariate and multivariate analyses of recurrence-free interval and overall survival.

\begin{tabular}{|c|c|c|c|c|}
\hline \multirow[b]{2}{*}{ Variables } & \multicolumn{2}{|c|}{ Univariate analysis } & \multicolumn{2}{|c|}{ Multivariate analysis } \\
\hline & HR $(95 \% \mathrm{CI})$ & P-value & $\mathrm{HR}(95 \% \mathrm{CI})$ & P-value \\
\hline \multicolumn{5}{|c|}{ Recurrence-free interval } \\
\hline $\begin{array}{l}\text { Age (years } \\
\text { High }\end{array}$ & $1.02(0.984-1.05)$ & 0.327 & & \\
\hline $\begin{array}{l}\text { pT stage } \\
\text { pT2,3,4 }\end{array}$ & $2.04(0.910-4.57)$ & 0.084 & & \\
\hline $\begin{array}{l}\text { Nodal stat } \\
\text { Positive }\end{array}$ & $9.10(3.88-21.3)$ & 0.007 & $8.92(3.79-21.0)$ & $<0.001$ \\
\hline $\begin{array}{l}\text { Nuclear gr } \\
\text { III }\end{array}$ & $1.91(0.640-5.67)$ & 0.247 & & \\
\hline $\begin{array}{l}\text { Lymphova } \\
\text { Positive }\end{array}$ & $5.17(0.697-38.4)$ & 0.108 & & \\
\hline $\begin{array}{r}\text { Progestero } \\
\text { Negative }\end{array}$ & $0.827(0.367-1.86)$ & 0.646 & & \\
\hline $\begin{array}{l}\text { Ki67 label } \\
\text { High }\end{array}$ & $1.03(1.02-1.05)$ & 0.003 & $1.03(1.01-1.06)$ & 0.004 \\
\hline $\begin{array}{c}\text { p53 status } \\
\text { Positive }\end{array}$ & $1.32(0.576-3.02)$ & 0.512 & & \\
\hline $\begin{array}{l}\text { Chemothe } \\
\text { Yes }\end{array}$ & $1.51(0.647-3.54)$ & 0.339 & & \\
\hline $\begin{array}{l}\text { Overall surv } \\
\text { Age (years }\end{array}$ & & & & \\
\hline High & $1.05(0.985-1.11)$ & 0.140 & & \\
\hline $\begin{array}{l}\text { pT stage } \\
\text { pT } 2,3,4\end{array}$ & $6.45(1.29-32.3)$ & 0.023 & $1.52(0.257-9.03)$ & 0.643 \\
\hline $\begin{array}{l}\text { Nodal stath } \\
\text { Positive }\end{array}$ & $40.0(7.94-201.0)$ & $<0.001$ & $29.5(4.91-177.0)$ & $<0.001$ \\
\hline $\begin{array}{l}\text { Nuclear gr } \\
\text { III }\end{array}$ & $4.05(0.740-22.2)$ & 0.107 & & \\
\hline $\begin{array}{l}\text { Lymphova } \\
\text { Positive }\end{array}$ & $27.2(0.009-84.3)$ & 0.420 & & \\
\hline $\begin{array}{r}\text { Progestero } \\
\text { Negative }\end{array}$ & $0.697(0.170-2.86)$ & 0.616 & & \\
\hline $\begin{array}{l}\text { Ki67 label } \\
\text { High }\end{array}$ & $1.04(1.01-1.08)$ & 0.021 & $1.04(0.996-1.09)$ & 0.074 \\
\hline $\begin{array}{l}\text { p53 status } \\
\text { Positive }\end{array}$ & $2.02(0.503-8.11)$ & 0.321 & & \\
\hline $\begin{array}{l}\text { Chemothe } \\
\text { Yes }\end{array}$ & $3.14(0.784-12.6)$ & 0.106 & & \\
\hline
\end{tabular}

HR, hazard ratio; CI, confidence interval.

Ki67 labeling index was marginally associated with OS (HR=1.04, 95\% CI: 0.996-1.09, P=0.074) (Table II).

The predictive value of the Ki67 labeling index should be determined when considering additional chemotherapy decisions. Therefore, whether Ki67 may be used to determine the likelihood of a poor prognosis among patients who did not receive chemotherapy, and who had undergone breast surgery before the Ki67 labeling index was adopted as a breast cancer guideline (18) for implementing decisions regarding adjuvant therapy. The ROC curve revealed an optimal Ki67 labeling index cut-off value of $20.0 \%$ for predicting recurrence in 138 patients who did not receive adjuvant chemotherapy (area under the curve $=0.650$; sensitivity, 66.7\%; specificity, 63.4\%) (Fig. 3A).

Comparison of clinicopathological parameters between Ki67 labeling index $<20$ and $\geq 20 \%$. At a cut-off value of $20.0 \%$, a 
A

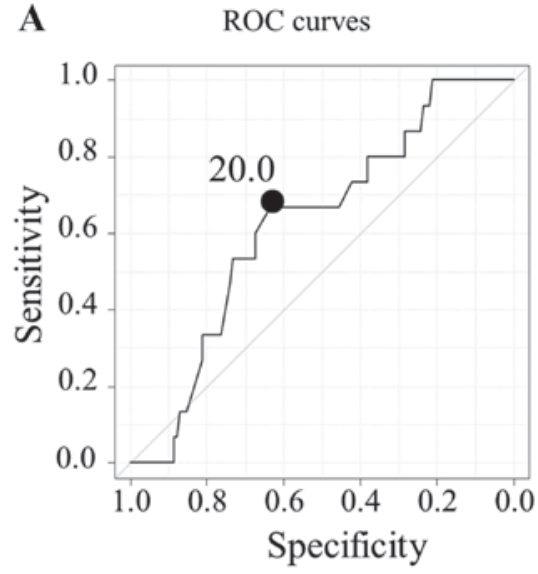

B

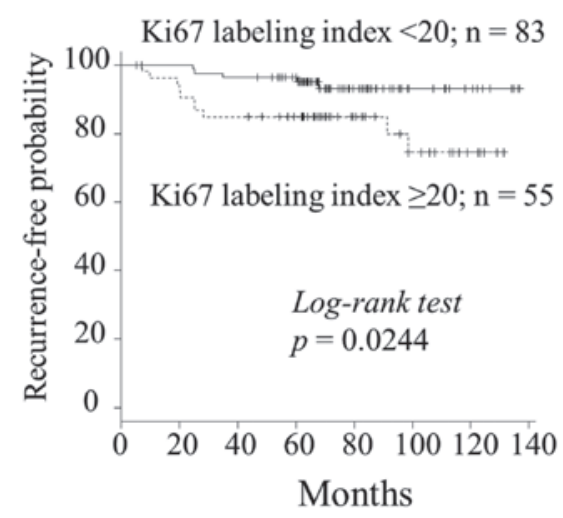

Figure 3. Recurrence and recurrence-free interval (RFI) determined from receiver operating characteristic (ROC) curves according to Ki67 labeling index cut-offs in patients prior to 2009 who did not receive adjuvant chemotherapy. (A) The optimal cut-off of the Ki67 labeling index is $20.0 \%$ ( $n=138$, area under the curve $=0.650$; sensitivity, $66.7 \%$; specificity, 63.4\%). (B) The 5-year RFI for patients with Ki67 $<20$ and $\geq 20 \%$ was 97.2 and $86.6 \%$, respectively $(\mathrm{P}=0.0244)$.

high Ki67 labeling index was significantly associated with large tumors, lymph node positivity and p53 positivity (Table III). The 5-year RFI for patients with Ki67 labeling indices $<20$ and $\geq 20 \%$ was 97.2 and $86.6 \%$, respectively $(P=0.0244$; Fig. 3B). The univariate analysis demonstrated that a high Ki67 labeling index ( $\geq 20 \%$ ), lymph node metastasis and PgR negativity were significantly worse prognostic factors for RFI ( $\mathrm{P}=0.0333,0.0116$ and 0.0573 , respectively) (Table IV).

\section{Discussion}

The clinical value of Ki67 and p53 as prognostic markers in patients with ER-positive and HER2-negative breast cancer was investigated. The present findings confirmed that Ki67 expression is a prognostic factor for both RFI and OS in patients with ER-positive and HER2-negative breast cancer. The multivariate model demonstrated that Ki67 expression remained significant for RFI, a trend was evident for OS, and these results were consistent with the majority of published data $(10,28)$.

The predictive value of $\mathrm{Ki} 67 \mathrm{IHC}$ for adjuvant treatment of ER-positive and HER2-negative breast cancer has not been investigated in a prospective, randomized study. In the present study, a cut-off Ki67 labeling index of $20.0 \%$ identi- fied patients with a poor prognosis among those who did not receive adjuvant chemotherapy. Although this retrospective study included significant selection bias for adjuvant chemotherapy, the results indicated that patients with a Ki67 labeling index $\geq 20.0 \%$ should not be treated with adjuvant endocrine therapy alone. Likewise, Criscitiello et al (29) retrospectively analyzed the ability of Ki67 to predict adjuvant chemotherapy in patients with ER-positive/HER2-negative, node-positive breast cancer, using propensity scores to minimize bias related to the non-random assignment of treatment. Their analysis of Subpopulation Treatment Effect Pattern Plots found that Ki67 was dichotomous at the $32 \%$ level. Certainly, not only the Ki67 labeling index but also nodal status, PgR status and other prognostic factors, should be considered in the decision regarding adjuvant treatment (7). Further prospective validation studies are required to evaluate the appropriateness of the Ki67 labeling index cut-off value as a predictive factor.

There is a lack of consensus regarding the use of the Ki67 labeling index, which results in inconsistencies in inter-laboratory methodology (11-13). In particular, the method of assessing Ki67 has been argued. It may be done by several scoring approaches: Hot-spot scoring, inclusion of hot spots in general across the section scoring, and by overall average score across the whole section only. A working party of the International Ki67 in Breast Cancer Working Group has been established to assess which method is more robust (30). Although it remains under evaluation, Honma et al (31) reported that Ki67 estimation at the 'hottest spot' was found to be superior to that determined by the average score across the whole section as a predictor of outcome in patients with ER-positive and HER2-negative breast cancer treated with tamoxifen. In the present study, hot-spot scoring was used, and it demonstrated the prognostic significance of the Ki67 labeling index. However, establishment of an international standard methodology for using Ki67 is required.

The results of the present study did not reveal a prognostic significance for $\mathrm{p} 53$. The prognostic significance of $\mathrm{p} 53$ protein expression in ER-positive and HER2-negative breast cancer has been reported in a limited number of studies (14-17). However, several items of information are required for the interpretation of $\mathrm{p} 53$ protein expression. The correlation between p53 accumulation measured using IHC and p53 mutations detected using sequencing has been estimated to be $<75 \%$ in breast cancer (32). Not all mutations yield a stable protein, and certain mutations lead to a truncated protein that cannot be detected using IHC. Done et al (33) demonstrated strong p53 nuclear staining in all tumors known to harbour missense mutations, but in no tumors with truncation mutations. Wild-type p53 may also accumulate in certain tumors as a result of a response to DNA damage or by binding to other cellular proteins (34). Moreover, at the single-tumor level, p53 mutations are distributed in a heterogeneous manner (35). It is necessary to collect evidence regarding p53 accumulation and establish the methodology for clinical practice. Further studies on p53 as a predictive factor for late recurrence and adjuvant chemotherapy are required, along with the findings of previous reports $(15,17)$.

This study's limitations include its retrospective design at a single institution, the heterogeneity of the administered treatments, and the short follow-up period. Nonetheless, a clear statistical significance was identified for the Ki67 labeling index. 
Table III. Comparison of clinicopathological parameters between Ki67 labeling index $<20$ and $\geq 20 \%$ in patients who did not receive chemotherapy $(\mathrm{n}=138)$.

\begin{tabular}{|c|c|c|c|}
\hline Variables & $\begin{array}{l}\text { Ki67 labeling index }<20 \% \\
(\mathrm{n}=83)\end{array}$ & $\begin{array}{l}\text { Ki67 labeling index } \\
(n=55)\end{array}$ & P-value \\
\hline Age, years (median $\pm \mathrm{SD}$ ) & $61.1 \pm 13.0$ & $62.7 \pm 13.1$ & 0.497 \\
\hline pT stage, n (\%) & & & 0.00420 \\
\hline $\mathrm{T} 1$ & $68(81.9)$ & $32(58.2)$ & \\
\hline $\mathrm{T} 2, \mathrm{~T} 3, \mathrm{~T} 4$ & $15(18.1)$ & $23(41.8)$ & \\
\hline Nodal status, n (\%) & & & 0.0236 \\
\hline Negative & $83(100)$ & $51(92.7)$ & \\
\hline Positive & $0(0.0)$ & $4(7.27)$ & \\
\hline Nuclear grade, $\mathrm{n}(\%)$ & & & 0.739 \\
\hline $\mathrm{I}, \mathrm{II}$ & $66(79.5)$ & $44(80.0)$ & \\
\hline III & $5(6.02)$ & $5(9.09)$ & \\
\hline Lymphovascular invasion, n (\%) & & & 0.296 \\
\hline Negative & $22(26.5)$ & $10(18.2)$ & \\
\hline Positive & $58(69.9)$ & $45(81.8)$ & \\
\hline Progesterone receptor status, n (\%) & & & 1.00 \\
\hline Negative & $16(19.3)$ & $11(20.0)$ & \\
\hline Positive & $68(81.9)$ & $44(80.0)$ & \\
\hline p53 status, n (\%) & & & $<0.001$ \\
\hline Negative & $68(81.9)$ & $25(45.5)$ & \\
\hline Positive & $15(18.1)$ & $30(54.5)$ & \\
\hline
\end{tabular}

Table IV. Univariate and multivariate analyses of the recurrence-free interval in patients who did not receive chemotherapy $(n=138)$.

\begin{tabular}{|c|c|c|c|c|}
\hline \multirow[b]{2}{*}{ Variables } & \multicolumn{2}{|c|}{ Univariate analysis } & \multicolumn{2}{|c|}{ Multivariate analysis } \\
\hline & HR $(95 \% \mathrm{CI})$ & P-value & HR $(95 \% \mathrm{CI})$ & P-value \\
\hline \multicolumn{5}{|l|}{ Age (years) } \\
\hline High & $1.03(0.985-1.07)$ & 0.216 & & \\
\hline \multicolumn{5}{|l|}{ pT stage } \\
\hline pT $2,3,4$ & $1.66(0.587-4.63)$ & 0.341 & & \\
\hline \multicolumn{5}{|c|}{ Nodal status } \\
\hline Positive & $6.84(1.54-30.5)$ & 0.0116 & $4.12(0.872-19.5)$ & 0.0739 \\
\hline \multicolumn{5}{|c|}{ Nuclear grade } \\
\hline III & $0.868(0.113-6.68)$ & 0.892 & & \\
\hline \multicolumn{5}{|c|}{ Lymphovascular invasion } \\
\hline Positive & $4.10(0.537-31.3)$ & 0.174 & & \\
\hline \multicolumn{5}{|c|}{ Progesterone receptor status } \\
\hline Negative & $2.74(0.970-7.74)$ & 0.0573 & & \\
\hline \multicolumn{4}{|c|}{ Ki67 labeling index } & 0.0785 \\
\hline \multicolumn{5}{|l|}{ p53 status } \\
\hline Positive & $1.05(0.357-3.06)$ & 0.935 & & \\
\hline
\end{tabular}

HR, hazard ratio; CI, confidence interval.

In conclusion, Ki67 was found to be an independent prognostic factor for patients with ER-positive and HER2-negative breast cancer, and its cut-off values for making a decision regarding adjuvant treatment were validated. 


\section{References}

1. Badve S and Nakshatri H: Oestrogen-receptor-positive breast cancer: Towards bridging histopathological and molecular classifications. J Clin Pathol 62: 6-12, 2009.

2. Hortobagyi GN: Treatment of breast cancer. N Engl J Med 339: 974-984, 1998

3. Early Breast Cancer Trialists' Collaborative Group: Tamoxifen for early breast cancer: An overview of the randomised trials. Early Breast Cancer Trialists' Collaborative Group. Lancet 351: 1451-1467, 1998

4. Mauri D, Pavlidis N, Polyzos NP and Ioannidis JP: Survival with aromatase inhibitors and inactivators versus standard hormonal therapy in advanced breast cancer: Meta-analysis. J Natl Cancer Inst 98: 1285-1291, 2006.

5. Cheang MC, Chia SK, Voduc D, Gao D, Leung S, Snider J, Watson M, Davies S, Bernard PS, Parker JS, et al: Ki67 index, HER2 status, and prognosis of patients with luminal B breast cancer. J Natl Cancer Inst 101: 736-750, 2009.

6. Azim HA Jr, Michiels S, Zagouri F, Delaloge S, Filipits M, Namer M, Neven P, Symmans WF, Thompson A, André F, et al: Utility of prognostic genomic tests in breast cancer practice: The IMPAKT 2012 Working Group Consensus Statement Ann Oncol 24: 647-654, 2013.

7. Goldhirsch A, Winer EP, Coates AS, Gelber RD, Piccart-Gebhart M, Thürlimann B, Senn HJ, Albain KS, Andre F, Bergh J, et al; Panel members: Personalizing the treatment of women with early breast cancer: Highlights of the St. Gallen International Expert Consensus on the Primary Therapy of Early Breast Cancer 2013. Ann Oncol 24: 2206-2223, 2013.

8. Domagala W, Markiewski M, Harezga B, Dukowicz A and Osborn M: Prognostic significance of tumor cell proliferation rate as determined by the MIB- 1 antibody in breast carcinoma: Its relationship with vimentin and p53 protein. Clin Cancer Res 2: 147-154, 1996.

9. Trihia H, Murray S, Price K, Gelber RD, Golouh R, Goldhirsch A, Coates AS, Collins J, Castiglione-Gertsch M and Gusterson BA; International Breast Cancer Study Group: Ki-67 expression in breast carcinoma: Its association with grading systems, clinical parameters, and other prognostic factors - a surrogate marker? Cancer 97: 1321-1331, 2003.

10. de Azambuja E, Cardoso F, de Castro G Jr, Colozza M, Mano MS, Durbecq V, Sotiriou C, Larsimont D, Piccart-Gebhart MJ and Paesmans M: Ki-67 as prognostic marker in early breast cancer: A meta-analysis of published studies involving 12,155 patients. Br J Cancer 96: 1504-1513, 2007.

11. Gnant M, Harbeck N and Thomssen C: St. Gallen 2011: Summary of the Consensus Discussion. Breast Care (Basel) 6: 136-141, 2011

12. Untch M, Gerber B, Möbus V, Schneeweiss A, Thomssen C, von Minckwitz G, Beckmann MW, Blohmer JU, Costa SD, Diedrich K, et al: Zurich Consensus: Statement of German Experts on St. Gallen Conference 2011 on Primary Breast Cancer (Zurich 2011). Breast Care (Basel) 6: 144-152, 2011.

13. Untch M, Gerber B, Harbeck N, Jackisch C, Marschner N, Möbus V, von Minckwitz G, Loibl S, Beckmann MW, Blohmer JU, et al: 13th St. Gallen international breast cancer conference 2013: Primary therapy of early breast cancer evidence, controversies, consensus - opinion of a German team of experts (Zurich 2013). Breast Care (Basel) 8: 221-229, 2013.

14. Millar EK, Graham PH, McNeil CM, Browne L, O'Toole SA, Boulghourjian A, Kearsley JH, Papadatos G, Delaney G, Fox C, et al: Prediction of outcome of early $\mathrm{ER}^{+}$breast cancer is improved using a biomarker panel, which includes Ki-67 and p53. Br J Cancer 105: 272-280, 2011.

15. Kobayashi T, Iwaya K, Moriya T, Yamasaki T, Tsuda H, Yamamoto J and Matsubara O: A simple immunohistochemical panel comprising 2 conventional markers, Ki67 and p53, is a powerful tool for predicting patient outcome in luminal-type breast cancer. BMC Clin Pathol 13: 5, 2013.

16. Boyle DP, McArt DG, Irwin G, Wilhelm-Benartzi CS, Lioe TF, Sebastian E, McQuaid S, Hamilton PW, James JA, Mullan PB, et al: The prognostic significance of the aberrant extremes of p53 immunophenotypes in breast cancer. Histopathology 65: 340-352, 2014.

17. Yamamoto M, Hosoda M, Nakano K, Jia S, Hatanaka KC, Takakuwa E, Hatanaka Y, Matsuno Y and Yamashita H: p53 accumulation is a strong predictor of recurrence in estrogen receptor-positive breast cancer patients treated with aromatase inhibitors. Cancer Sci 105: 81-88, 2014.
18. Cancer Genome Atlas Network: Comprehensive molecular portraits of human breast tumours. Nature 490: 61-70, 2012

19. Goldhirsch A, Glick JH, Gelber RD, Coates AS, Thürlimann B and Senn HJ; Panel members: Meeting highlights: International Expert Consensus on the primary therapy of early breast cancer 2005. Ann Oncol 16: 1569-1583, 2005.

20. Goldhirsch A, Wood WC, Gelber RD, Coates AS, Thürlimann B and Senn HJ; 10th St. Gallen conference: Progress and promise: Highlights of the International Expert Consensus on the primary therapy of early breast cancer 2007. Ann Oncol 18: 1133-1144, 2007.

21. Goldhirsch A, Ingle JN, Gelber RD, Coates AS, Thürlimann B and Senn HJ; Panel members: Thresholds for therapies: Highlights of the St. Gallen International Expert Consensus on the primary therapy of early breast cancer 2009. Ann Oncol 20: 1319-1329, 2009.

22. Goldhirsch A, Wood WC, Coates AS, Gelber RD, Thürlimann B and Senn HJ; Panel members: Strategies for subtypes - dealing with the diversity of breast cancer: Highlights of the St. Gallen International Expert Consensus on the Primary Therapy of Early Breast Cancer 2011. Ann Oncol 22: 1736-1747, 2011.

23. National Comprehensive Cancer Network: Breast Cancer. http://ww.nccn.org/professionals/physician_gls/f_guidelines.asp

24. The Japanese Breast Cancer Society: General Rules for Clinical and Pathological Recording of Breast Cancer. 16th edition. Kanehara Shuppan, Tokyo, 2008.

25. Allred DC, Harvey JM, Berardo M and Clark GM: Prognostic and predictive factors in breast cancer by immunohistochemical analysis. Mod Pathol 11: 155-168, 1998.

26. Iwaya $K$, Tsuda $H$, Hiraide $H$, Tamaki $K$, Tamakuma $S$, Fukutomi T, Mukai K and Hirohashi S: Nuclear p53 immunoreaction associated with poor prognosis of breast cancer. Jpn J Cancer Res 82: 835-840, 1991.

27. Kanda Y: Investigation of the freely available easy-to-use software 'EZR' for medical statistics. Bone Marrow Transplant 48: 452-458, 2013.

28. Yerushalmi R, Woods R, Ravdin PM, Hayes MM and Gelmon KA: Ki67 in breast cancer: Prognostic and predictive potential. Lancet Oncol 11: 174-183, 2010.

29. Criscitiello C, Disalvatore D, De Laurentiis M, Gelao L, Fumagalli L, Locatelli M, Bagnardi V, Rotmensz N, Esposito A, Minchella I, et al: High Ki-67 score is indicative of a greater benefit from adjuvant chemotherapy when added to endocrine therapy in luminal B HER2 negative and node-positive breast cancer. Breast 23: 69-75, 2014.

30. Dowsett M, Nielsen TO, A'Hern R, Bartlett J, Coombes RC, Cuzick J, Ellis M, Henry NL, Hugh JC, Lively T, et al; International Ki-67 in Breast Cancer Working Group: Assessment of Ki67 in breast cancer: Recommendations from the International Ki67 in Breast Cancer Working Group. J Natl Cancer Inst 103: 1656-1664, 2011.

31. Honma N, Horii R, Iwase T, Saji S, Younes M, Ito Y and Akiyama F: Ki-67 evaluation at the hottest spot predicts clinical outcome of patients with hormone receptor-positive/HER2-negative breast cancer treated with adjuvant tamoxifen monotherapy. Breast Cancer 22: 71-78, 2015.

32. Norberg T, Lennerstrand J, Inganäs $M$ and Bergh J: Comparison between p53 protein measurements using the luminometric immunoassay and immunohistochemistry with detection of p53 gene mutations using cDNA sequencing in human breast tumors. Int J Cancer 79: 376-383, 1998.

33. Done SJ, Arneson CR, Ozçelik H, Redston M and Andrulis IL: p53 protein accumulation in non-invasive lesions surrounding p53 mutation positive invasive breast cancers. Breast Cancer Res Treat 65: 111-118, 2001.

34. Lacroix M, Toillon RA and Leclercq G: p53 and breast cancer, an update. Endocr Relat Cancer 13: 293-325, 2006.

35. Geisler S, Lønning PE, Aas T, Johnsen H, Fluge O, Haugen DF, Lillehaug JR, Akslen LA and Børresen-Dale AL: Influence of TP53 gene alterations and c-erbB-2 expression on the response to treatment with doxorubicin in locally advanced breast cancer. Cancer Res 61: 2505-2512, 2001. 